\title{
A case of primary non-small cell lung cancer with synchronous small cell lung cancer
}

\author{
HANLI WANG ${ }^{*}$ and ZHIWEI LU* \\ Department of Respiratory Disease, Yijishan Hospital of Wannan Medical College, Wuhu, Anhui 241001, P.R. China
}

Received February 5, 2015; Accepted April 7, 2016

DOI: $10.3892 / \operatorname{mco} .2016 .859$

\begin{abstract}
Synchronous multiple primary lung cancer is an uncommon and difficult to distinguish from metastatic disease. The present study reported an extremely rare case of a 66-year-old male with non-small lung cell cancer in the left lobe and synchronous small cell lung cancer in the right lobe. The diagnosis of multiple primary lung cancer not only depends on biopsy pathology, but also requires molecular biology results. This is of great significance for the management and prognosis of multiple primary lung cancer. The management of patients with non-small cell lung cancer-small cell lung cancer produces certain unique challenges, which may require individualized treatment modality that may not strictly comply with standard practices in the setting of a single tumor.
\end{abstract}

\section{Introduction}

Lung cancer is the most common cause of cancer-associated mortality worldwide (1). Multiple primary lung cancer (MPLC) is rare (2), ranging between 0.2 and $20 \%$ (3), which has $\geq 2$ primary lung cancers with different pathological types (4). Two manifestations of MPLC exist: Metachronous or synchronous, and depending on which, their morphology and histology are similar (5). To distinguish MPLC from metastatic cancer in the lung or recurrence is difficult, however, it is of great significance for therapeutic management and prognosis. The diagnosis of MPLC not only depends on biopsy pathology, but also often requires molecular biology techniques, including DNA polity, gene mutations and microsatellite alteration (6-9). The present study reported a case of primary non-small cell lung cancer (NSCLC) in the left lobe

Correspondence to: Dr Zhiwei Lu, Department of Respiratory Disease, Yijishan Hospital of Wannan Medical College, 2 Zhesanxi Road, Wuhu, Anhui 241001, P.R. China

E-mail: zhiweiluboss@sina.com

*Contributed equally

Key words: synchronuos multiple primary lung cancer, individualized treatment, management of small lung cell cancer and synchronous small cell lung cancer (SCLC) in the right lung lobe. The patient with synchronous MPLC tolerated two cycles of a chemotherapy regimen that consisted of etoposide $\left(100 \mathrm{mg} / \mathrm{m}^{2}\right.$ of body-surface area) from one to three days and nedaplatin $\left(75 \mathrm{mg} / \mathrm{m}^{2}\right.$ of body-surface area) on day one. The patient exhibited a favorable response, including loss of the dry cough and a reduction in the two lesions, observed by chest computed tomography (CT) during follow-up.

\section{Case study}

A 66-years-old male was referred to the Department of Respiratory Disease at Yijishan Hospital of Wannan Medical College (Wuhu, China) in April 2015 with a dry cough accompanied with blood in phlegm over the previous 1 month. The previous medical history of the patient was uneventful, with the exception of a 40 pack/year history of smoking. Physical examination revealed a rough respiratory murmur in each lung. Laboratory findings were within normal limits, with the exception of prostate special antigen (PSA) at $5.35 \mathrm{ng} / \mathrm{ml}$. Chest CT images obtained in April 2015 revealed an irregular soft-tissue mass with a $9.6 \mathrm{~cm}$ maximum diameter, internal uniformity density in the middle-low right lobe close to pulmonary hilum, and a nodular high-density shadow with a $2.5 \mathrm{~cm}$ maximum diameter that was a lobulated lesion in the left upper lobe (Fig. 1A and B). The patient was positive for metastasis to the mediastinal lymph node. Fiber bronchoscopic biopsy was performed a few days later, which revealed squamous cell carcinoma in the left lobe and SCLC in the right lobe (Fig. 2). Immunohistochemical staining of SCLC revealed a marked positivity for AE1/AE3, Syn, cluster of differentiation 56, thyroid transcription factor-1, p63 (few), Ki-67 (80\%) and EMA. By contrast, the SCLC was negative for $\mathrm{CgA}(-)$, NapsinA and p40. The patient refused gene detection of squamous cell carcinoma in the left lobe due to expense. The patient tolerated two cycles of a chemotherapy regimen that consisted of etoposide (100 $\mathrm{mg} / \mathrm{m}^{2}$ of body-surface area) from 1-3 days and nedaplatin $\left(75 \mathrm{mg} / \mathrm{m}^{2}\right.$ of body-surface area) on day 1 . The patient exhibited a favorable response, including reduction in the dry cough, and reduction of the two lesions in the chest CT performed during follow-up (Fig. 1C and D). A limitation of the present case report is that only two cycles of etopiside combined with nedaplatin were administered in May and June 2015. The treatment with chemotherapy was interrupted due to the large expenditure. 

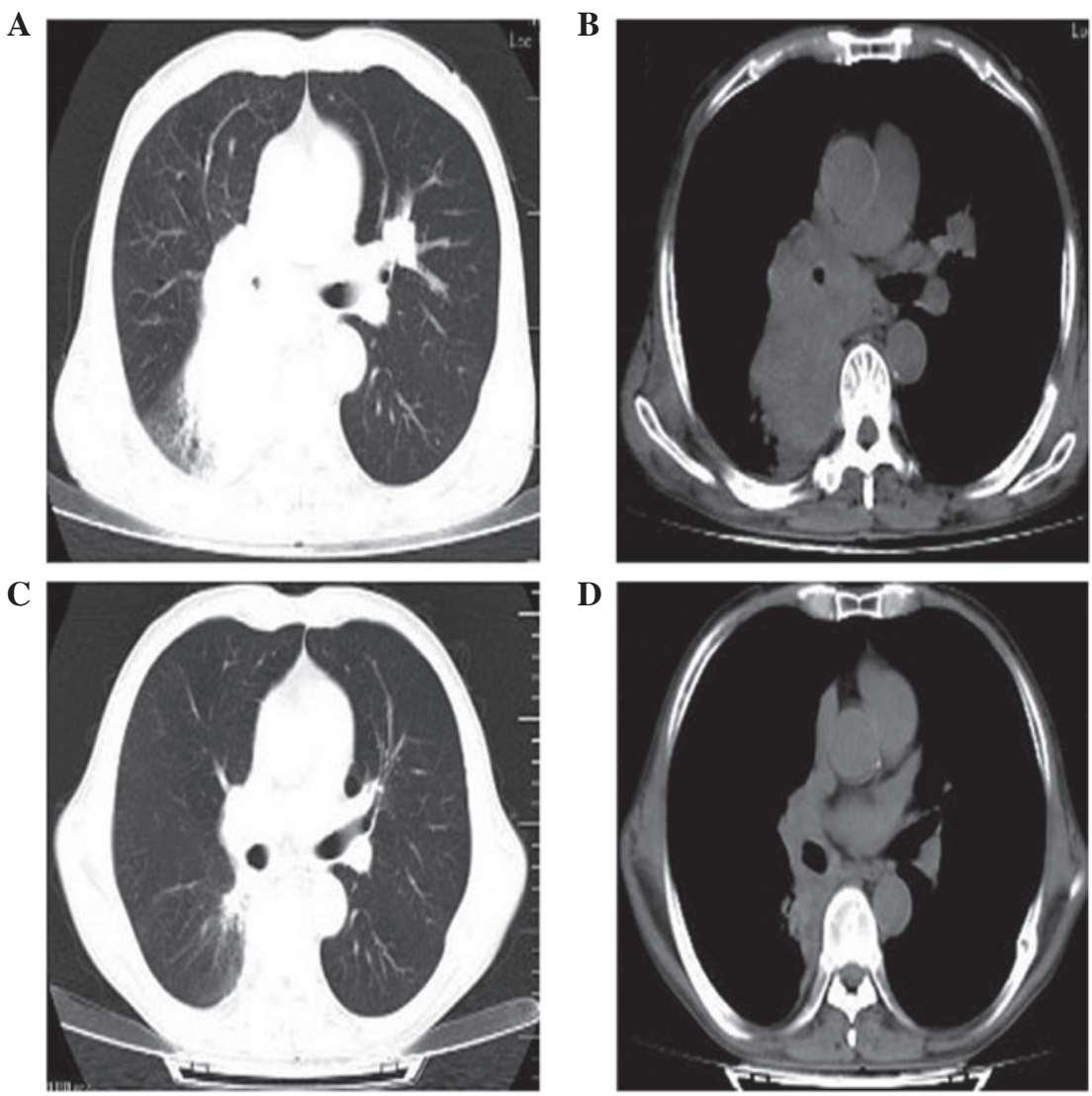

Figure 1. Chest CT scans performed at different stages. (A and B) A chest CT scan performed in April 2015 showing a $96 \mathrm{~mm}$ tumor in the middle-low right lobe, and a $25 \mathrm{~mm}$ tumor in the left upper lobe, multiple mediastinal lymph nodes, mediastinal and lung windows. (C and D) A chest CT scan performed in June 2015 revealed a $28 \mathrm{~mm}$ tumor in the middle-low right lobe, and a patchy tumor of unknown size, multiple mediastinal lymph nodes, mediastinal and lung windows. CT, computed tomography.
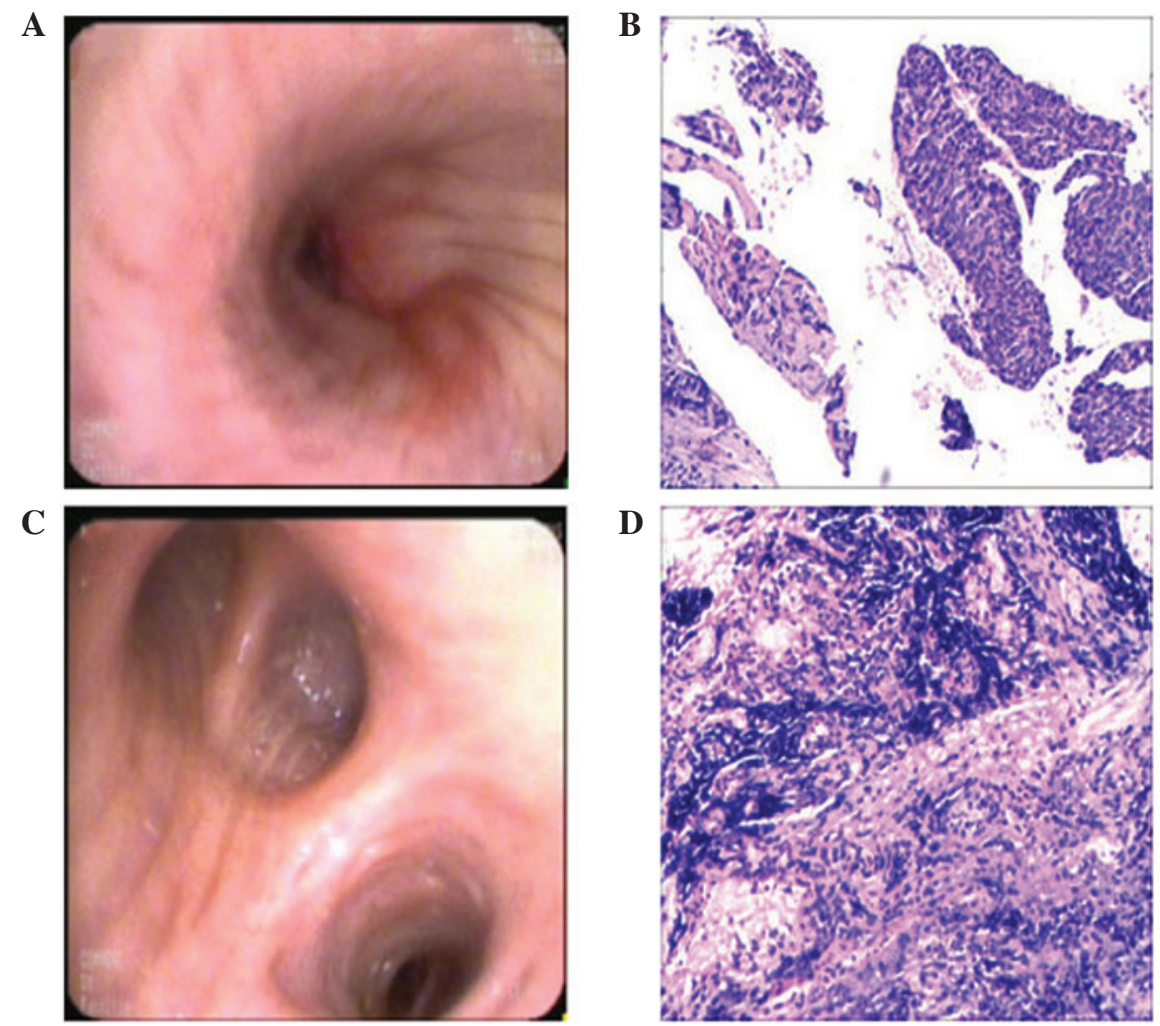

Figure 2. Fiber bronchoscopy and biopsy pathology. (A) A new lesion was observed in the left upper lobe. (B) Hematoxylin and eosin staining revealed squamous cell carcinoma in the left lobe. (C) A new lesion was observed in the right middle lobe. (D) Hematoxylin and eosin staining revealed small cell cancer in the right lobe. 


\section{Discussion}

The present study reported an uncommon case of a 66-year-old male patient diagnosed with MPLC. Fiber bronchoscopy pathological biopsy revealed two completely different pathological types, which were squamous cell lung carcinoma in the left lobe and SCLC in the right lobe. The patient tolerated two cycles of a chemotherapy regimen that consisted of etoposide (100 mg/m $/ \mathrm{m}^{2}$ of body-surface area) from 1-3 days and nedaplatin ( $75 \mathrm{mg} / \mathrm{m}^{2}$ of body-surface area) on day 1 . The patient had a favorable response, including loss of the dry cough and reduction in the two lesions observed by chest CT during the follow-up.

To the best of our knowledge, MPLC is a special type of primary lung carcinoma occurring in one or both lung lobes, which may be $\geq 2$ different pathological types (4). Two manifestations in MPLC exist: Metachronous or synchronous, and depending on which, their morphology and histology are similar (5). The mechanism of the MPLC remains to be fully understood, and only a few studies have addressed that it may be associated with field cancerization $(10,11)$. Chang et al (12) reported the links between MPLC, and the epidermal growth factor receptor (EGFR) and p53 genes. Somatic alterations in EGFR were demonstrated, which can not only greatly improve the clonality assessment, but also affect the management of patients with MPLC. In addition, it is of significance to distinguish MPLC from metastatic carcinoma in the lung for the management and prognosis. The incidence of MPLC is attributed to the development of higher-resolution chest imaging techniques, positron emission computed tomography-CT, fiber bronchoscopy biopsy and percutaneous lung biopsy by CT fluoroscopy. The initial diagnostic criteria were established in 1975 by Martin and Melamed (4), and were updated by the American College of Chest Physicians (ACCP) (13). Different pathological categories is of great importance for the identification of MPLC (14). However, following the Martin-Melamed and ACCP criteria only distinguish certain MPLC types from metastases. Girard et al (7) confirmed that 3/7 patents with paired adenocarcinoma exhibited multiple primary lung tumors by means of EGFR/KRAS mutation testing. When it comes to similar pathological types, MPLC can be confirmed by means of DNA polity, gene mutations and microsatellite alteration $(6-9,15,16)$. No standard guidelines exist for the management of MPLC. However, the current case demonstrated a few important principles. SCLC generally exhibits a higher growth fraction, a more rapid doubling time and earlier development of widespread metastases when compared with NSCLC (17). SCLC is highly sensitive to initial chemotherapy, particularly in the most common regimen (etoposide plus cisplatin), which can provide symptomatic improvement and prolonged survival $(18,19)$. However, Veronesi et al (20) indicated that outcomes following surgery in patients with early SCLC were comparable to those in patients with NSCLC. The patient with an enlarged mediastinal lymph node exhibited squamous carcinoma combined with SCLC, therefore, that chemotherapy with etoposide and nedaplatin was performed. Therefore, if an MPLC patient is confirmed with synchronous SCLC and NSCLC, the appropriate chemotherapy regimen must be selected as quickly as possible.

In conclusion, the present study reported a case of MPLC with simultaneous SCLC and NSCLC. The management of patients with MPLC requires highly individualized treatment plans that are dissimilar to standard practices in the setting of a single tumor. Consideration must be given to the chemotherapy regimen that improve symptoms and prolongs survival.

\section{Acknowledgements}

The authors would like to thank Renguang Pei (Department of Interventional Therapy, Yijishan Hospital of Wannan Medical College, Wuhu, China) for providing assistance with writing and organization of this manuscript.

\section{References}

1. Jemal A, Siegel R, Ward E, Murray T, Xu J, Smigal C and Thun MJ: Cancer statistics, 2006. CA Cancer J Clin 56: 106-130, 2006.

2. Detterbeck FC, Postmus PE and Tanoue LT: The stage classification of lung cancer: Diagnosis and management of lung cancer, 3rd ed: American college of chest physicians evidence-based clinical practice guidelines. Chest 143 (5 Suppl): e191S-e210S, 2013.

3. Rea F, Zuin A, Callegaro D, Bortolotti L, Guanella G and Sartori F: Surgical results for multiple primary lung cancers. Eur J Cardiothorac Surg 20: 489-495, 2001.

4. Martini $\mathrm{N}$ and Melamed MR: Multiple primary lung cancers. J Thorac Cardiovasc Surg 70: 606-612, 1975.

5. Riquet M, Cazes A, Pfeuty K, Ngabou UD, Foucault C, Dujon A and Banu E: Multiple lung cancers prognosis: What about histology. Ann Thorac Surg 86: 921-926, 2008.

6. Arai J, Tsuchiya T, Oikawa M, Mochinaga K, Hayashi T, Yoshiura K, Tsukamoto K, Yamasaki N, Matsumoto K, Miyazaki T and Nagayasu T: Clinical and molecular analysis of synchronous double lung cancers. Lung Cancer 77: 281-287, 2012.

7. Girard N, Ostrovnaya I, Lau C, Park B, Ladanyi M, Finley D, Deshpande C, Rusch V, Orlow I, Travis WD, et al: Genomic and mutational profiling to assess clonal relationships between multiple non-small cell lung cancers. Clin Cancer Res 15: 5184-5190, 2009.

8. Girard N, Deshpande C, Azzoli CG, Rusch VW, Travis WD, Ladanyi $\mathrm{M}$ and Pao W: Use of epidermal growth factor receptor/Kirsten rat sarcoma 2 viral oncogene homolog mutation testing to define clonal relationships among multiple lung adenocarcinomas: Comparison with clinical guidelines. Chest 137: 46-52, 2010.

9. Shen C, Xu H, Liu L, Zhou Y, Chen D, Du H, Han Z and Che G: 'Unique trend' and 'contradictory trend' in discrimination of primary synchronous lung cancer and metastatic lung cancer. BMC Cancer 13: 467, 2013.

10. Pasic A, Vonk-Noordegraaf A, Risse EK, Postmus PE and Sutedja TG: Multiple suspicious lesions detected by autofluorescence bronchoscopy predict malignant development in the bronchial mucosa in high risk patients. Lung Cancer 41: 295-301, 2003.

11. Braakhuis BJ, Tabor MP, Kummer JA, Leemans CR and Brakenhoff RH: A genetic explanation of Slaughter's concept of field cancerization: Evidence and clinical implications. Cancer Res 63: 1727-1730, 2003.

12. Chang YL, Wu CT, Lin SC, Hsiao CF, Jou YS and Lee YC: Clonality and prognostic implications of p53 and epidermal growth factor receptor somatic aberrations in multiple primary lung cancers. Clin Cancer Res 13: 52-58, 2007.

13. Kozower BD, Larner JM, Detterbeck FC and Jones DR: Special treatment issues in non-small cell lung cancer: Diagnosis and management of lung cancer, 3rd ed: American college of chest physicians evidence-based clinical practice guidelines. Chest 143 (5 Suppl): e369S-e399S, 2013.

14. Shen C, Wang X, Tian L, Zhou Y, Chen D, Du H, Wang W, Liu L and Che G: 'Different trend' in multiple primary lung cancer and intrapulmonary metastasis. Eur J Med Res 20: 17, 2015.

15. Ono K, Sugio K, Uramoto H, Baba T, Ichiki Y, Takenoyama M, Hanagiri T, Oyama $\mathrm{T}$ and Yasumoto K: Discrimination of multiple primary lung cancers from intrapulmonary metastasis based on the expression of four cancer-related proteins. Cancer 115: 3489-3500, 2009. 
16. Chen D, Mei L, Zhou Y, Shen C, Xu H, Niu Z and Che G: A novel differential diagnostic model for multiple primary lung cancer: Differentially-expressed gene analysis of multiple primary lung cancer and intrapulmonary metastasis. Oncol Lett 9: 1081-1088, 2015.

17. Kalemkerian GP, Akerley W, Bogner P, Borghaei H, Chow LQ, Downey RJ, Gandhi L, Ganti AK, Govindan R, Grecula JC, et al: Small cell lung cancer. J Natl Compr Canc Netw 11: 78-98, 2013.
18. Hann CL and Rudin CM: Management of small-cell lung cancer: Incremental changes but hope for the future. Oncology (Williston Park) 22: 1486-1492, 2008

19. Jackman DM and Johnson BE: Small-cell lung cancer. Lancet 366: 1385-1396, 2005.

20. Veronesi G, Bottoni E, Finocchiaro G and Alloisio M: When is surgery indicated for small-cell lung cancer. Lung Cancer 90: 582-589, 2015. 